\section{SAT0381 NEUTROPHIL-RELATED BIOMARKERS DISCRIMINATE SEPTIC ARTHRITIS FROM OTHER INFLAMMATORY ARTHRITIDES: DATA FROM THE BOSSA TRIAL}

A. Baillet ${ }^{1}$, C. Trocmé $^{2}$, A. Courtier ${ }^{3}$, C. Nguyen ${ }^{3}$, B. Toussaint ${ }^{2}$, O. Epaulard ${ }^{4}$. ${ }^{1}$ GREPI University Grenoble-Alpes (UGA) EA74 08, France; ${ }^{2}$ TheReX/TIMC-IMAG (UMR 5525) Laboratory, UGA; Laboratory of Biochimie des Enzymes et des Protéines, Centre Hospitalier Universitaire Grenoble Alpes, France; ${ }^{3}$ Sinnovial SAS; ${ }^{4}$ Infectious Disease department, Grenoble Hospital, Grenoble, France

Background: Septic arthritis is a life threatening purulent invasion of a joint by an infectious agent which produces arthritis. If untreated, septic arthritis causes structural damage to the joint. Unfortunately no relevant biomarkers are available for the diagnosis of this disabling condition. We aimed at determining whether calprotectin (S100A8/A9) and Human neutrophil alpha-defensins (HNP1-3) could discriminate septic from other inflammatory arthritides

Objectives: We aimed at determining whether calprotectin (S100A8/A9) and Human neutrophil alpha-defensins (HNP1-3) could discriminate septic from other inflammatory arthritides

Methods: Patients joint effusions for which septic arthritis was suspected were prospectively collected in Grenoble Hospital. Patients with inflammatory synovial fluid (i.e. with white blood cell $>2000 / \mathrm{mm} 3$ and $>80 \%$ polymorphonuclear neutrophils $(\mathrm{PMN})$ ) were included in this trial. Diagnosis of septic arthritis was retained if bacteria were cultured from inflammatory synovial fluid and/or blood samples. Diagnosis of pseudo gout was retained when pyrophosphate calcium crystals were observed in inflammatory synovial fluid. Diagnosis of rheumatoid arthritis was retained according to rheumatologist opinion.

C Reactive protein (CRP), both neutrophil-related proteins calprotectin and human neutrophil alpha-defensins (HNP1-3) levels were assessed in synovial fluids.

Threshold for biomarkers were determined by ROC curve analysis. Sensibility, Specificity, Positive (PPV) and Negative (NPV) Predictive Values at a pre specified threshold were calculated. Biomarkers with $p$ value $\leq 0.05$ were included into a multivariate model. Multivariate logistic regression with stepwise selection was performed to build the final combined model.

Results: A total of 74 patients were included: septic arthritis $(n=26)$, pseudo gout $(n=28)$ and Rheumatoid arthritis $(n=20)$. Patients with septic arthritis group were more likely to be male $(69 \%$ vs. $31 \%, p=0.030)$, were younger (median age (range) 65.5 (27-84) vs. 72.5 (33-91), $\mathrm{p}=0.047)$ ), displayed higher synovial fluid PMN count $(9,600$ (1,800-68000) vs. 6560 (750-22500, $p=0.047))$., LR+12.2 and LR- 0.26.

Calprotectin was significantly increased in patients with septic arthritis (190 (0.1$247)$ vs. $62(0-208) \mathrm{mg} / \mathrm{L}, \mathrm{p}<0.001$, figure 1$)$ whereas only a trend of an HNP1-3 rise was shown in arthritis septic (6.8 (0.5-56.6) vs. $3.4(0.1-6.4) \mathrm{mg} / \mathrm{L}, \mathrm{p}=0.050)$. Optimal Thresholds for calprotectin, HNP1-3, and synovial fluid PMN were respectively $150 \mathrm{mg} / \mathrm{L}, 6.5 \mathrm{mg} / \mathrm{L}$ and $7000 / \mathrm{mm}^{3}$.

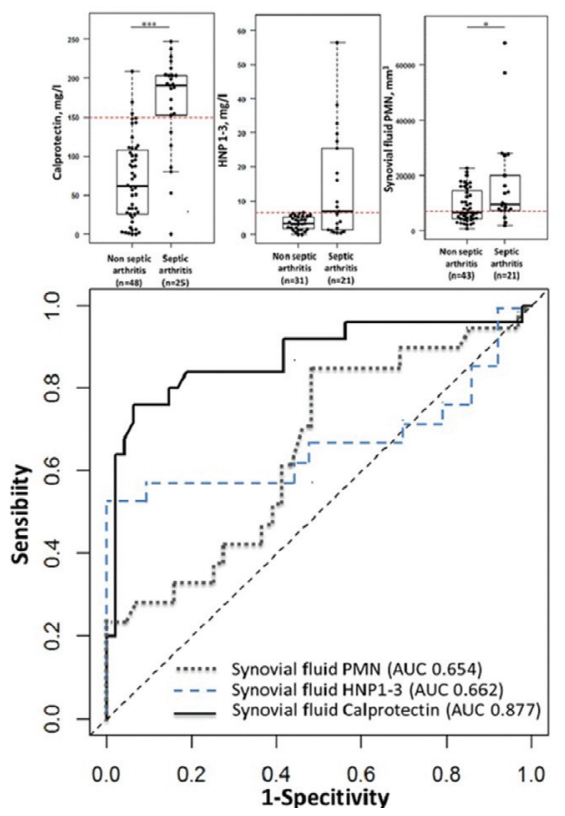

In the multivariate model, including calprotectin, HNP1-3, synovial fluid PMN count and gender, calprotectin was the only biomarker discriminating septic arthritis from non-septic inflammatory arthritides with $76 \%$ sensitivity, $94 \%$ specificity, $86 \%$ PPV and $88 \%$ NPV.
Conclusions: Our data show here that synovial fluid calprotectin is a relevant biomarker to discriminate septic arthritis from other inflammatory arthritides. This biomarker should be tested in an independent cohort.

Acknowledgements: The authors thank Sylvie Papacatzis for her help in the study.

Disclosure of Interest: None declared

DOI: 10.1136/annrheumdis-2018-eular.6705

\section{SAT0382 UTILITY OF NEUTROPHIL CD64 \& SERUM TREM-1 IN DISTINGUISHING BACTERIAL INFECTION FROM DISEASE FLARE IN SLE AND ANCA ASSOCIATED VASCULITIS}

S. Ajmani ${ }^{1}$, H. Singh ${ }^{2}$, S. Chaturvedi' ${ }^{2}$, R. Mishra ${ }^{2}$, M.K. Rai ${ }^{2}$, A. Jain ${ }^{2}$, D.P. Misra ${ }^{1}$, V. Agarwal ${ }^{2} .{ }^{1}$ Clinical Immunology; ${ }^{2}$ Sanjay Gandhi Post Graduate Institute, Lucknow, New Delhi, India

Background: Treating physician is challenged to differentiate between disease activity vs. infection as to the cause of fever in patients with SLE and ANCA associated vasculitis (AAV). Presently, there is no biomarker to reliably differentiate between them.

Objectives: We aimed to determine the usefulness of CD64 (FcyR1) expression on neutrophils and STREM-1 (soluble triggering receptor expressed on myeloid cells) in serum in distinguishing bacterial infection from disease flare in SLE and AAV.

Methods: 20 healthy controls and patients of SLE and AAV admitted to our unit either with disease flare or bacterial infection were recruited over a period of 1 year. Neutrophil CD64 expression was measured by flow cytometry and STREM by ELISA from blood samples collected on the day of admission.

Results: Among the 76 patients included in the study 51 (SLE-35 and AAV-16) had disease flare while 25 (SLE-21 and AAV-4) had infection. 72\% had fever at presentation. The percentage of neutrophils with CD64 expression and their mean fluorescence intensity in patients with infection were significantly $(p<0.05)$ higher as compared to those without infection and controls (Table-1). The sensitivity and specificity of CD64 expression on neutrophils to diagnose bacterial infection (using a cut off value of $30 \%$ ) was $85 \%$ and $84 \%$, respectively. Whereas, the sensitivity and specificity of procalcitonin was $75 \%$ and $85 \%$ respectively. There was no significant difference in soluble TREM-1 levels between the two groups. Total leucocyte count (TLC), ESR, CRP, C3, C4 levels were not significantly different between disease flare and infection group. On subgroup analysis (Table-2) patients of SLE with infection had a higher CRP, TLC and Procalcitonin compared to those with disease flare $(p<0.5)$. ROC curves are depicted in figure 1 .

Table-1- Comparison of various parameters between healthy controls, patients with active disease and infection

\begin{tabular}{|c|c|c|c|}
\hline Characteristic & $\begin{array}{l}\text { Active disease } \\
\quad(n-51)\end{array}$ & $\begin{array}{l}\text { Infection } \\
(\mathrm{n}-25)\end{array}$ & $\begin{array}{l}\text { Healthy } \\
\text { controls } \\
(n-20)\end{array}$ \\
\hline $\begin{array}{l}\text { CD64 expression on neutrophils } \\
\text { (\%) }\end{array}$ & $7.7(2.6-13)$ & $68.8(56.9-86.5)^{*}$ & $7.05(1.4-9.5)$ \\
\hline $\begin{array}{l}\text { Mean fluorescence intensity of } \\
\text { CD64 }\end{array}$ & $456(20-986)$ & $1037(229-1828)^{*}$ & $\begin{array}{l}99.5(54.7- \\
140.7)\end{array}$ \\
\hline sTREM-1 (pg/ml) & $1184(717-1609)^{\star *}$ & $899(531-1284)^{\star *}$ & $\begin{array}{c}255.1(95.1- \\
634.8)\end{array}$ \\
\hline Procalcitonin (pg/ml) & $\begin{array}{l}157.7(115.1- \\
209.3)^{\star \star}\end{array}$ & $\begin{array}{c}301(141.8- \\
339.3)^{*}\end{array}$ & $77.6(61-101.8)$ \\
\hline $\begin{array}{l}\text { Total leucocyte count (cells/ } \\
\mathrm{mm}^{3} \text { ) }\end{array}$ & $\begin{array}{c}9700(4600- \\
12400)\end{array}$ & $\begin{array}{c}10750(6000- \\
15000)\end{array}$ & - \\
\hline CRP (mg/L) & $1.9(0.86-6.05)$ & $5.4(1.83-8.9)$ & - \\
\hline $\mathrm{ESR}(\mathrm{mm} / \mathrm{hr})$ & $70(30-103)$ & $75(55-110)$ & - \\
\hline
\end{tabular}

Abstract SAT0382 - Table 2. Subgroup analysis of patients with SLE and ANCA associated vasculitis

\begin{tabular}{lcccc}
\hline Variable & $\begin{array}{c}\text { SLE with } \\
\text { active disease } \\
(\mathbf{n}=35)\end{array}$ & $\begin{array}{c}\text { SLE with } \\
\text { Infection }(\mathbf{n}=21)\end{array}$ & $\begin{array}{c}\text { AAV with active } \\
\text { disease }(\mathbf{n}=16)\end{array}$ & $\begin{array}{c}\text { AAV with } \\
\text { infection }(\mathbf{n}=4)\end{array}$ \\
\hline $\mathrm{CRP}(\mathrm{mg} / \mathrm{dl})$ & $1.3(0.39-2.3)$ & $5.54(1.8-9.2)^{*}$ & $7.3(2.64-10.5)$ & $11.7(2.08-$ \\
& & & & $20.85)$ \\
$\mathrm{TLC}(\mathrm{cellls} /$ & $6400(3400-$ & $11000(5925-$ & $12200(10550-$ & $12000(10,300-$ \\
$\left.\mathrm{mm}^{3}\right)$ & $9500)$ & $16650)^{*}$ & $20400)$ & $20100)$ \\
$\mathrm{nCD}^{*}(\%)$ & $9.42(3-13.7)$ & $69.4(59-87.1)^{*}$ & $4.25(2.27-8.5)$ & $76(42.5-80.9)$ \\
Procalcitonin & $174(101-204)$ & $316(231-345)^{*}$ & $172(127-257)$ & $104(86-356)$
\end{tabular}

$(\mathrm{pg} / \mathrm{ml})$

${ }^{*} \mathrm{p}<0.05$ vs. SLE with disease flare

All values expressed as median (25th-75th Interquartile range) 